\title{
THE MONITORING AND CONTROL OF AN ARM CRANK SYSTEM USING FUZZY LOGIC FOR MULTI-HANDICAPPED YOUTHS WITH MENTAL RETARDATION
}

\author{
JIANN-SHING SHIEH, JEN-TSANG HUNG
}

Department of Mechanical Engineering, Yuan Ze University, Taoyuan, Taiwan

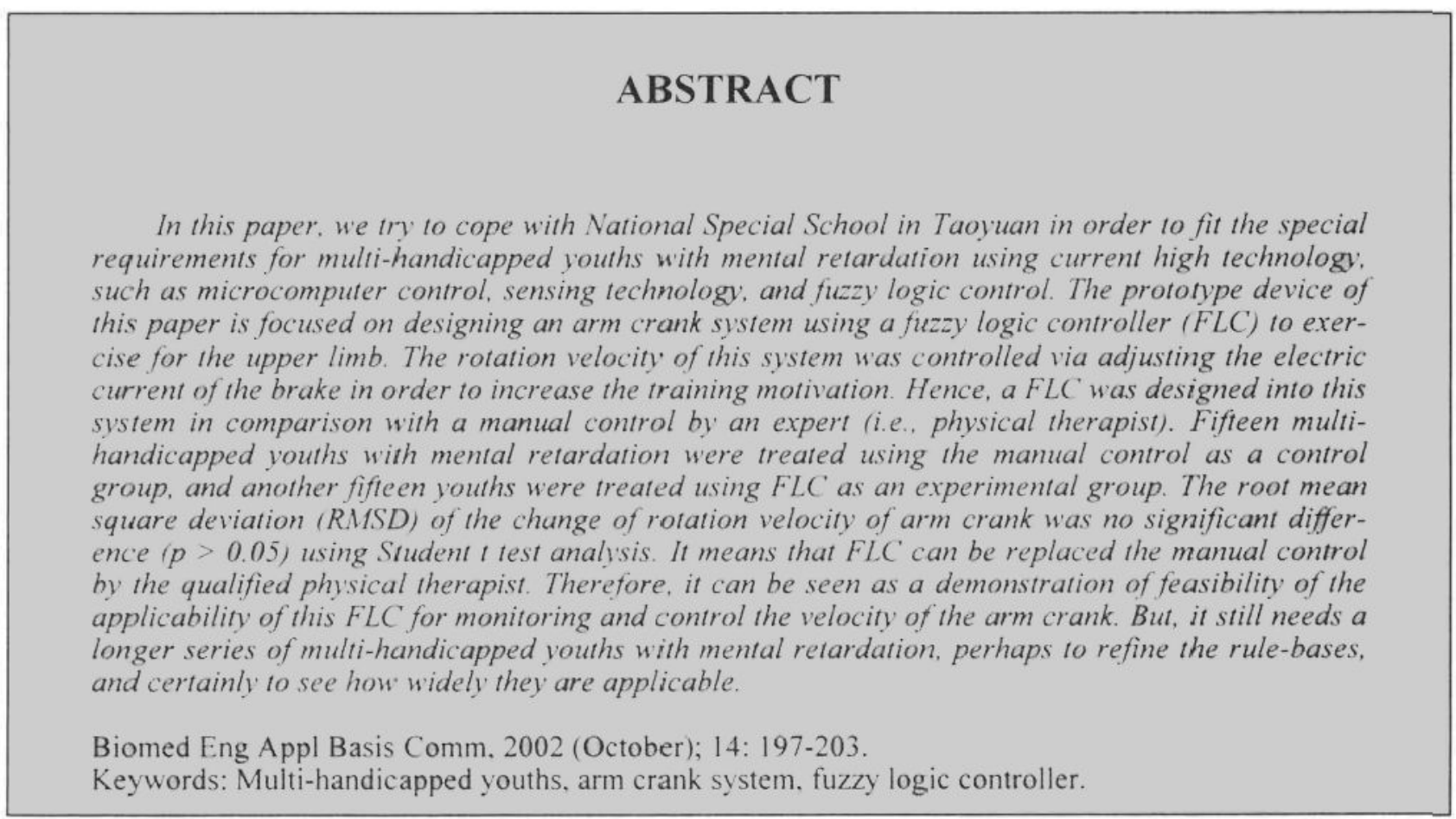

\section{INTRODUCTION}

The National Special School in Taoyuan is to educate the youths of moderate/severe mental retardation and multi-handicap (ex., crippled and cerebral palsied). In the rehabilitation room of school, there are several exercise training and assistive devices for multi-handicapped students with mental retardation in order to exercise their upper and lower limbs. Also, a qualified physical therapist is always present during

Received: August 8, 2002; Accepted: Oct. 8, 2002 Correspondence: Dr. Jiann-Shing Shieh, Department of Mechanical Engineering, Yuan Ze University, Taoyuan, Taiwan. training exercise. However, the devices in the rehabilitation room are mostly bought from either commercial exercise or rehabilitation devices combined with some parts of special design. Hence, they are very difficult to fit the multi-handicapped students with mental retardation due to their special requirements. Nevertheless, there are several disadvantages for students of using these devices according to the school's experience during the past few years, such as lack of training motivation, difficult to teach the standard operation, large individual variations, and lack of quantitative evaluation.

One problem with feedback control in biomedicine is that there are enormous patient-to-patient variations in dynamic model parameters. This is compounded by large time-varying parameters for an individual patient during the course in the rehabilitation 


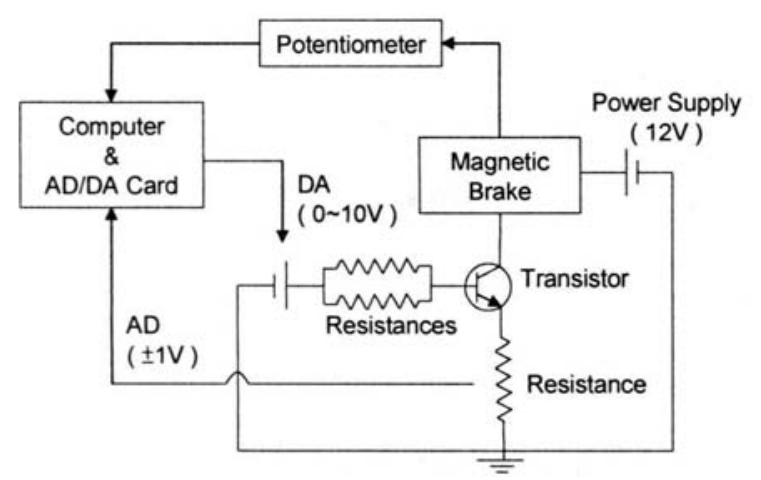

Fig 1. The schematic diagram of an arm crank system for either right or left arm

room. This makes it difficult to design a fixedparameter PID controller which will be suitable in all cases. This led to the need to investigate self-adaptive control strategies, and later self-organizing controllers. A model-based self-tuning PID approach has been implemented in a series of clinical trials [1]. Although the self-tuning trials have been successful, they have involved considerable work in selecting the design parameters and mathematical models of the patient. However, the lack of training motivation, difficult to teach the standard operation, large individual variations, and lack of quantitative evaluation for the youths of moderate/severe mental retardation and multihandicap in the rehabilitation room of school have made this approach more difficult.

Fuzzy logic control (FLC) is a simple and effective technique for controlling non-linear and uncertain processes $[2,3]$. Fuzzy logic not only accommodates uncertainty by dealing in imprecise, qualitative terms such as low, medium and high but also provides control rules which are easy to understand and modify when discussing with experts. In 1965, fuzzy set theory was introduced by Zadeh [4] and it has been used successful in a number of control applications $[5,6]$. Much of human problem solving and inference is uncertain, inexact and partial, i.e. it is fuzzy. In many circumstances where decisions have to be made, the facts are far from precise. This paradigm seems to be specially suitable for biomedical processes [7-10], since it depends upon expert experience which are not precisely quantifiable, such as patient's subjective sensations, interpretation of clinical signs and effects of instrument accuracy.

Hence, the prototype device of this paper is focused on designing an arm crank system using a FLC to exercise for the upper limb [11-15]. Except the basic requirements of these exercise training devices (such as pedaling and rotating), we still need to consider the sensing and biofeedback, computer fuzzy logic control (especially for the individual control of left and right sides), and automated record and keeping system. Hopefully, the research results can not only solve the current problems in National Special School in Taoyuan but also apply to other special schools, handicapped people, and elderly society in Taiwan.

\section{CONTROL SYSTEM DESIGN}

The current devices in the rehabilitation room for arm cranks are mostly bought from either commercial exercise or rehabilitation devices combined with some parts of special design. They are very difficult to fit the multi-handicapped students with mental retardation due to their special requirements. Hence, we redesigned the commercial product in order to fit their special requirements, especially for the individual control of left and right sides. Three parts have been designed into the arm crank system as shown in Fig. 1, which are two magnetic bake devices for controlling the resistances of each arm, two potentiometer sensors for measuring the each side of the velocity of the arm crank, and an electronic circuit for computer control of this system.

Manual adjustment of the arm crank prescription is currently the method by which an expert physical therapist can be accommodated. In this paper, we not only keep a manual control but also develop a fuzzy logic control applied in this device in order to replace an expert that controls the rotation velocity of an arm crank via a signal from the electric current of the brake of this device as shown in Fig. 2.

Fig. 3 shows the FLC control structure. The

Table. 1 The qualified physical therapists' rule-base for controlling the rotation velocity of an arm crank system using change of electric current of the brake inside the device

\begin{tabular}{|c|c|c|c|c|}
\hline \multirow{2}{*}{\multicolumn{2}{|c|}{$\Delta$ Current }} & \multicolumn{3}{|c|}{ Rate } \\
\hline & & $S$ & SB & B \\
\hline \multirow{5}{*}{$\Delta$ Rate } & NB & NB & NS & NS \\
\hline & NS & NS & $Z$ & $Z$ \\
\hline & $\mathrm{Z}$ & $Z$ & $\bar{Z}$ & PS \\
\hline & PS & $Z$ & PS & PS \\
\hline & PB & PS & PS & PB \\
\hline
\end{tabular}


fuzzy logic controller was designed to control the rotation velocity of the arm crank exercise via a signal from the electric current of the brake. Control rules, membership functions and defuzzification are three essential elements in the fuzzy logic control. To perform fuzzy inference and describe the arm crank control system, we chose two inputs which were the rotation velocity (Rate) and the change of the rotation velocity ( $\Delta$ Rate) of each arm, and one output which was the change of the electric current of the brake ( $\Delta$ Current) of each arm. In order to fuzzify the inputs and output, the rotation velocity was divided into three levels which were the big (B), between small and big (SB), and small (S). There is no any negative fuzzy set because of the non-feasible nature for rotation velocity. And, the change of rotation velocity was divided into five levels which were the negative big (NB), negative small (NS), zero (Z), positive small (PS), and positive big (PB). Also, the change of the electric current of the brake was divided into five levels which were the negative big (NB), negative small (NS), zero (Z), positive small (PS), and positive big (PB). According to the qualified physical therapists' experience, the following fifteen rules were developed to control the arm crank system as shown in Table 1. There are many shapes of possible membership functions, such as triangle, trapezoid etc. which can be used in the fuzzy logic controller. For simplicity and popularity, a triangle shape is used and a 25 percent overlap for contiguous fuzzy sets is reckoned [16] as shown in Fig. 4 for two inputs (Rate and $\Delta$ Rate), and one output ( $\Delta C$ Current).

When Rate and $\Delta$ Rate have been obtained, one can decide which quantized levels belong to them. There are two main procedures for the rules implication and inference which are used in most controllers, Max-Min and Max-Product procedures [17]. The former method was adopted in this study. Also, the inference engine works by using Gupta et al's [18] method, which involves the decomposition of multivariable fuzzy system into a set of one-dimensional systems. The input, output variables and fuzzy relations are described by the following equations:

$$
\begin{aligned}
& R_{i j}=\underset{k=1}{\vee p}\left[\mathrm{X}_{i}(k) \wedge \mathrm{Y}_{j}(k)\right] \\
& \mathrm{Y}_{j}={ }_{i=1}^{m}\left(\mathrm{X}_{i} \circ R_{i j}\right)
\end{aligned}
$$

where $\mathrm{Xi}$ is the fuzzy value of the $\mathrm{i}$-input variable; $\mathrm{Yj}$ is the fuzzy value of the $j$-output variable; $R i j$ is the fuzzy relation of the $i$-input and $j$-output variable; $m$ are the number of input variables; $p$ are the number of rules; ${ }^{-} \quad$ is the max-min composition; $\wedge$ is the min operator; $v$ is the max operator.

Finally, there are two main methods for defuzzification procedures, mean of maximum (MOM) and centre of area (COA) [19]. The latter procedure has been adopted because it gives smoother signals. Therefore, the equation of COA procedure for the control input can be written in the following equation [20]:

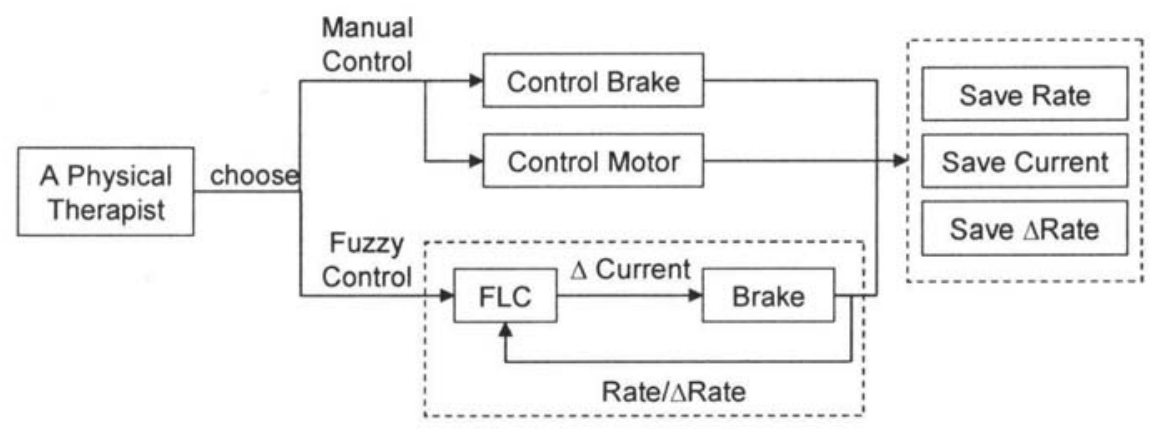

Fig. 2 The block diagram of manual control and fuzzy logic control of an arm crank system

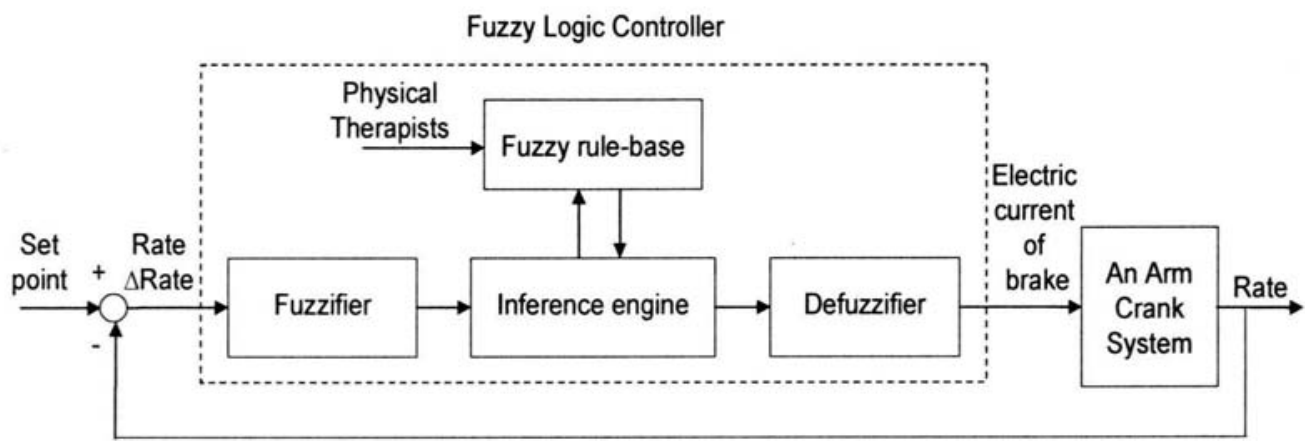

Fig. 3 A fuzzy logic controller structure of an arm crank system 


$$
I=\frac{\sum_{1}^{n}(M n \times U n)}{\sum_{1}^{n} M n}
$$

Where $M$ is the membership function; $U$ is the universe of discourse; $\boldsymbol{n}$ is the number of rules.

\section{PATIENTS AND METHODS}

Thirty multi-handicapped youths with mental retardation was divided into two groups. Group 1 (i.e., 15 youths) was the control group using the manual control by a qualified physical therapist. Group 2 (i.e., 15 youths) was the experimental group using a fuzzy logic control. During 10 min training exercise experiments either a manual or FLC control, a qualified physical therapist involved in the study was always present and responsible for standard monitoring of the multi-handicapped youths with mental retardation. Also, one investigator who designed this monitoring and control system is always present and responsible for handling any device or computer malfunction in order to bring the system back to control by the qualified physical therapist. The analog signals were done via PCL-812PG ADDA card (Advantech Co. Ltd, Taipei, Taiwan) which were interfaced to the arm crank system. The whole system was programmed in language "Visual Basic" and an IBM compatible computer was used for collection, display, control and storage of data of an arm crank system as shown in Fig. 5 , which was installed in National Special School in Taoyuan. In addition, the whole system was still under supervision by the qualified physical therapist.

\section{RESULTS}

Fifteen multi-handicapped youths with mental retardation using manual control as group 1 and another fifteen youths using FLC control as group 2 were studied at $10 \mathrm{~min}$ training exercise period. The root mean square deviation (RMSD) of the change of rotation velocity of arm crank was calculated in these two groups for each experiment. The mean (SD) of RMSD of the change of rotation velocity for the group 1 and group 2 methods as shown in Table 2 were 0.02410 (0.01146) and $0.02650(0.00896) \mathrm{rad} / \mathrm{s}$, respectively. The RMSD of the change of rotation velocity of arm crank was no significant difference $(p>0.05)$ using Student $t$ test analysis. It means that FLC can be replaced the manual control by the qualified physical therapist. Finally, the full graphical results from two clinical trials are shown in Fig. 6 to demonstrate the performance of rotation velocity, change of rotation velocity and change of current of the arm crank system during the manual and (a)

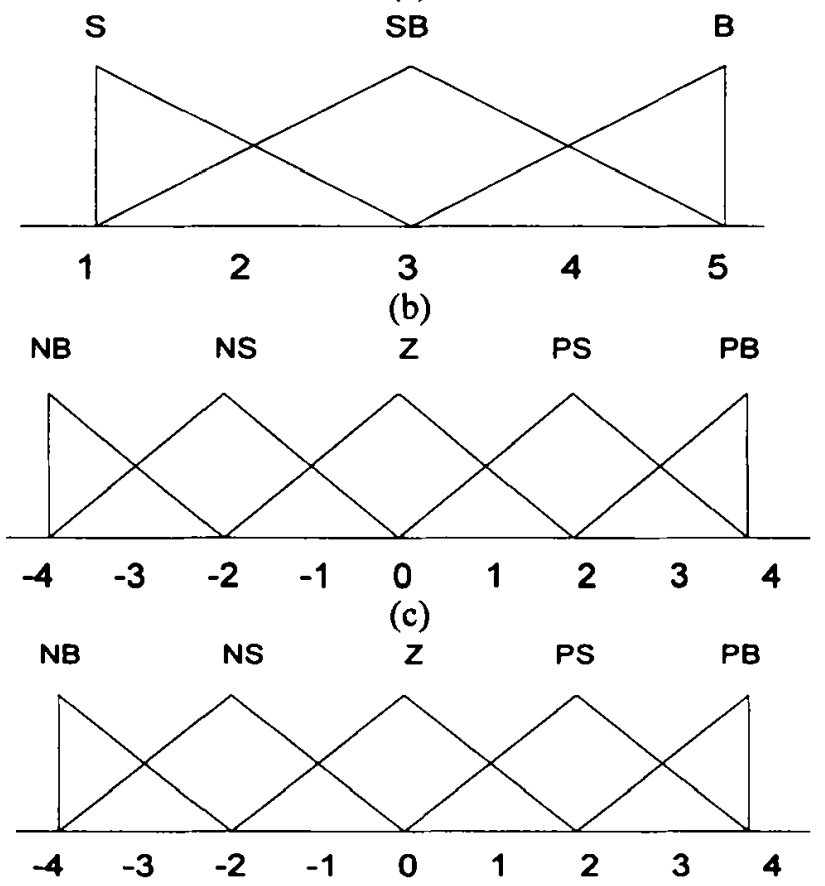

Fig. 4 Membership functions of two inputs and one output (a) Rate (b) $\Delta$ Rate (c) $\Delta$ Current

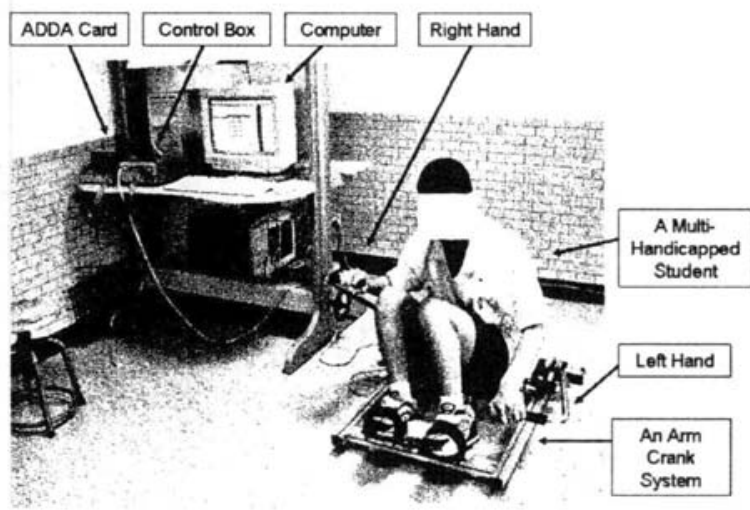

Fig. 5. An IBM compatible computer used for collection, display, control and storage of data for an arm crank system during a clinical trial in National Special School in Taoyuan.

FLC control.

\section{DISCUSSIONS}

Currently, the fuzzy rules were derived from expert experience and have been shown to be similar to the qualified physical therapist in the clinical trials. However, there are some drawbacks to this design approach. Firstly, a reliable linguistic model of the 
Table 2 The root mean square deviation (RMSD) of the change of rotation velocity of arm crank system for different groups (Group 1: Manual control; Group 2: Fuzzy logic control)

\begin{tabular}{|c|c|c|}
\hline Patient No. & RMSD of Group 1 & RMSD of Group 2 (rad/s) \\
\hline 1 & 0.01586 & 0.02091 \\
\hline 2 & 0.01968 & 0.01749 \\
\hline 3 & 0.01178 & 0.02323 \\
\hline 4 & 0.01920 & 0.02123 \\
\hline 5 & 0.05844 & 0.02567 \\
\hline 6 & 0.02929 & 0.02374 \\
\hline 7 & 0.01739 & 0.02487 \\
\hline 8 & 0.02204 & 0.02522 \\
\hline 9 & 0.03597 & 0.01035 \\
\hline 10 & 0.01630 & 0.02212 \\
\hline 11 & 0.01652 & 0.02820 \\
\hline 12 & 0.01941 & 0.04520 \\
\hline 13 & 0.02603 & 0.03411 \\
\hline 14 & 0.02354 & 0.04106 \\
\hline 15 & 0.03001 & 0.03405 \\
\hline Mean & 0.02410 & 0.02650 \\
\hline SD & 0.01146 & 0.00896 \\
\hline$t$-test & & $p=0.54$ \\
\hline
\end{tabular}

physical therapist's control strategy may not always be obtainable. Secondly, some significant system changes may be outside the physical therapist's experience. Thirdly, some system combined with multihandicapped youths with mental retardation may always have large uncertainty due to characteristics of inter-variations. Therefore, the applications of fuzzy controllers are limited and they need to be enhanced. Hence, much research will have to be carried out especially in the area of self-tuning rules. There are many publications [21-23] investigating this area of selforganizing fuzzy logic control (SOFLC). It can provide an adaptive rule-learning capability to complement a fuzzy logic control strategy. Using SOFLC will permit more accurate control of an arm crank system to benefit multi-handicapped youths with mental retardation.

Movement and position of limbs are controlled by electric signals traveling back and forth between the muscles and peripheral and central nervous system. When pathologic conditions arise in the motor system, whether in the spinal cord, the motor neurons, the muscle, or the neuromuscular junctions, the characteristics of the electrical signals in the muscle change. Careful registration and study of electrical signals in muscle (i.e., electromyograms) can thus be a valuable aid in discovering and diagnosing abnormalities not only in the muscles but also in the motor system as a whole. Electromyography (EMG) is the registration and interpretation of the muscle action potentials [24]. Hence, the future work in our arm crank system is needed to consider not only the monitoring EMG signals but also the using the EMG as a biofeedback signal into system

\section{CONCLUSION}

Clinically this FLC system was useful. It provided the similar RMSD of the change of rotation velocity of an arm crank compared with the manual control. It can reduce the need for the qualified physical therapist to spend time controlling the rotation velocity of an arm crank system. Also, it can be seen as a demonstration of feasibility of the applicability of this FLC for monitoring and control the rotation velocity of the arm crank. But, it still needs a longer series of multihandicapped youths with mental retardation, perhaps to refine the rule-bases, and certainly to see how widely they are applicable.

\section{ACKNOWLEDGEMENTS}

The authors wish to thank National Science Council (NSC) in Taiwan (Grant Number: NSC892614-E-155-001) for supporting this research. Also, the authors would like to thank the National Special School in Taoyuan for cooperating during this research period. 
(a)

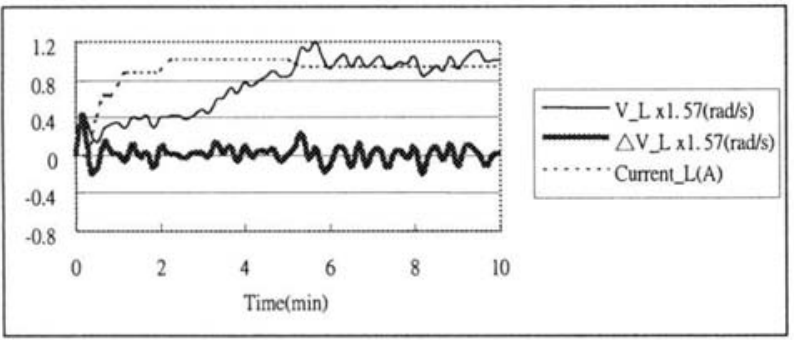

(b)

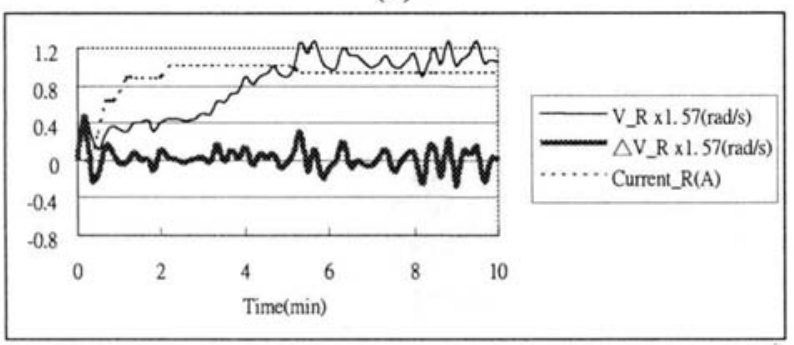

(c)

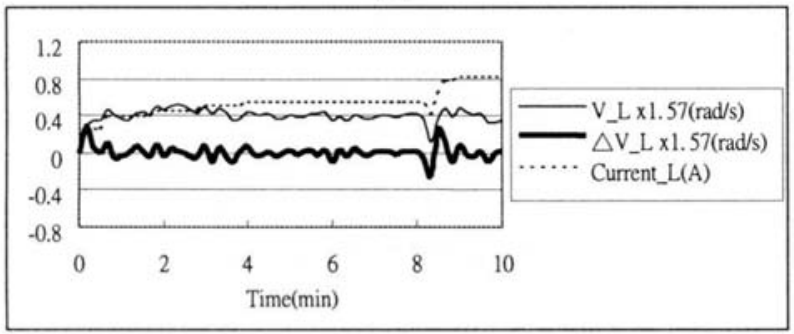

(d)

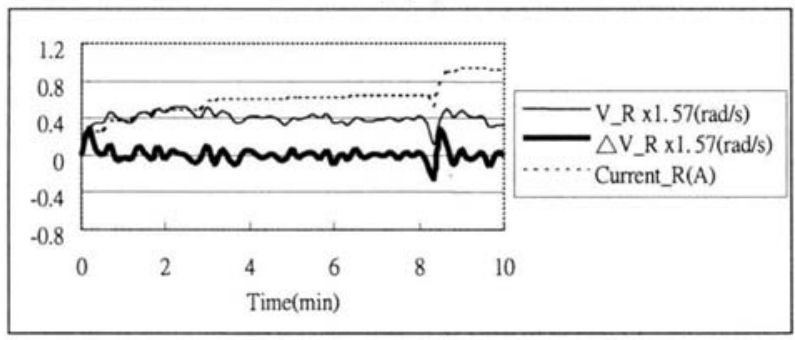

Fig. 6 The performance of rotation velocity, change of rotation velocity and change of current of the arm crank system during the manual and FLC control (a) Manual control of left arm (b) Manual control of right arm (c) FLC control of left arm (d) FLC control of right arm. Notation in the figures: $V \_L$, the rotation velocity of the left arm; $\Delta V_{-} L$, the change of rotation velocity of the left arm; Current_L, the electric current of the brake of the left arm.

\section{REFERENCES}

1. Denai M, Linkens DA, Asbury AJ, MacLead, AD and Gray WM: Self-tunung PID control of atracu- rium induced muscle relaxation in surgical patients, IEE Proceeding PtD 1990; 137: 261-72.

2. Asbury AJ and Tzabar Y: Fuzzy logic: new ways of thinking for anaesthesia. Br. J Anaesth 1995; 75: $1-2$.

3. Martine JF: Fuzzy control in anaesthesia. Journal of Clinical Monitoring 1994; 10:77-80.

4. Zadeh LA: Fuzzy Sets. Information and Control 1965; 8:338-353.

5. Lee CC: Fuzzy logic in control systems: Fuzzy logic controller-Part I. IEEE Trans. Syst. Man Cybern. 1990; 20(2): 404-418.

6. Lee CC: Fuzzy logic in control systems: Fuzzy logic controller-Part II. IEEE Trans. Syst. Man Cybern. 1990; 20 (2): 419-435.

7. Mason DG, Ross JJ, Edards ND, Linkens DA and Reilly CS: Self-learning fuzzy control of atracurium-induced neuromuscular block during surgery. Medical \& Biological Engineering \& Computing 1997; 35: 498-503.

8. Shich JS, Abbod MF, Linkens DA and Peacock JE: Hierarchical fuzzy-based support system for anaesthesia monitoring and control. IEE Proc.-Control Theory and Appl., 1999; 146(3): 265-272.

9. Shieh JS, Fan SZ, Chang LW and Liu CC: Hierarchical rule-based monitoring and fuzzy logic control for neuromuscular block. Journal of Clinical Monitoring and Computing 2000; 16: 583-592.

10. Shieh JS, Chang LW, Wang MS, Wang YP, Yang YP and Sun WZ: Pain model and fuzzy logic patient-controlled analgesia in shock wave lithotripsy. Medical \& Biological Engineering \& Computing 2002, 40: 128-136.

11.Lee S, Agah A and Bekey G: IROS: An intelligent rehabilitative orthotic system for cerebravascular accident. Systems, Man and Cybernetics, Conference Proceedings, IEEE International Conference on 1990, pp. $815-819$.

12. Noritsugu $\mathrm{T}$ and Tanaka $\mathrm{T}$ : Application of rubber artificial muscle manipulator as a rehabilitation robot. Mechatronics, IEEE/ASME Transactions on 1997, vol.2, pp.259-267.

13. Noritsugu T, Tanaka T and Yamanaka T: Application of rubber artificial muscle manipulator as a rehabilitation robot. Robot and Human Communication, 5th IEEE International Workshop on 1996, pp.112-117.

14. Boissy P, Bourbonnais D, Gravel D, Arsenault AB and Leblanc $\mathrm{M}$ : A static dynamometer measuring simultaneous torques exerted at the upper limb. IEEE Transactions on Rehabilitation Engineering 1998; 6: 309-315.

15. Reinkensmeyer DJ, Dewald JPA and Rymer WZ: Guidance-based quantification of arm impairment following brain injury: a pilot study. IEEE Transactions on Rehabilitation Engineering 1999; 7: 1-11.

16. Kosko B: Neural networks and fuzzy systems, 
Prentice-Hall International, Inc., Singapore, 1991.

17. Dombi J: Membership function as an evaluation. Fuzzy Sets and Systems 1990; 35: 1-21.

18. Gupta M M, Kiszka JB and Trojan GM: Multivariable structure of fuzzy control systems. IEEE Trans. on Systems, Man, and Cybernetics 1986, SMC-16 (5): 638-656.

19. Braae $M$ and Rutherford DA: Fuzzy relation in a control setting. Kybernetes 1978; 7(3): 185-188.

20. Li YF and Lau CC: Development of fuzzy algorithms for servo systems. IEEE Control Systems Magazine 1989; 9(4): 65-72.

21.Procyk TJ and Mamdani EH: A linguistic selforganizing process controller. Automatica 1979;15:
15-30.

22. Linkens DA and Abbod MF: Self-organing fuzzy logic control and the selection of its scaling factors. Transaction of the Institute of Measurements and Control 1992; 14(3): 114-125.

23. Shieh JS, Linkens DA and Peacock JE: Hierarchical rule-based and self-organizing fuzzy logic control of anaesthesia. IEEE Transaction on Systems, Man, and Cybernetics-Part C: Applications and Reviews 1999; 29(1): 98-109.

24. Henneberg K: Principles of electromyography. In: Bronzino, JD, Ed. The Biomedical Engineering Handbook, CRC Press, 1995, pp. 191-200. 